\title{
Influence of photoperiods on the growth rate and biomass productivity of green microalgae
}

\author{
Izabela Krzemińska Barbara Pawlik-Skowrońska • \\ Magdalena Trzcińska $\cdot$ Jerzy Tys
}

Received: 22 April 2013/Accepted: 22 August 2013/Published online: 14 September 2013

(C) The Author(s) 2013. This article is published with open access at Springerlink.com

\begin{abstract}
The effect of different photoperiods: $24 \mathrm{~h}$ illumination and a 12:12-h light/dark (12L:12D) cycle on the growth rate and biomass productivity was studied in five algal species: Neochloris conjuncta, Neochloris terrestris, Neochloris texensis, Botryococcus braunii and Scenedesmus obliquus. The green microalgae examined differ in the reproduction mode. Continuous illumination stimulated the growth of B. braunii and S. obliquus more effectively than the growth of the microalgal species from the genus Neochloris. However, under shorter duration of light of the same intensity (12L:12D cycle), the growth of all the three species of Neochloris was stimulated. Under continuous illumination, the specific growth rate in the first phase of B. braunii and S. obliquus cultures was higher than the growth rate of Neochloris, whereas under the 12L:12D cycle, the specific growth rate of all the three Neochloris species was generally higher than that in $B$. braunii and $S$. obliquus. As a result, the light regime influenced algal biomass productivity differently. The maximum biomass productivity was obtained in $B$. braunii and $S$. obliquus cultures carried out at continuous illumination. All the Neochloris species produced biomass more efficiently at the $12 \mathrm{~L}: 12 \mathrm{D}$ cycle, which was two-threefold
\end{abstract}

I. Krzemińska · J. Tys

Institute of Agrophysics, Polish Academy of Sciences,

Doświadczalna 4, 20-290 Lublin, Poland

e-mail: i.krzeminska@ipan.lublin.pl

B. Pawlik-Skowrońska ( $\square)$

Department of Hydrobiology, University of Life Sciences in

Lublin, Dobrzańskiego 37, 20-262 Lublin, Poland

e-mail:pawlik@poczta.umcs.lublin.pl

B. Pawlik-Skowrońska · M. Trzcińska

Polish Academy of Sciences Centre for Ecological Research,

Experimental Station, Niecała 18, 20-080 Lublin, Poland higher than that of B. braunii and S. obliquus. The unicellular species of the green microalgae from the genus Neochloris, examined for the first time in this study, are promising prospective objects for algal biotechnology.

Keywords Green microalgae - Light regime · Biomass productivity $\cdot$ Autotrophic cultivation

\section{Introduction}

The increasing demand for alternative energy sources increases the interest in biofuel production. One of the research objectives undertaken is biofuel production from microalgal biomass [1,2]. Microalgal biomass may be converted into a variety of biofuels. Biochemical conversion of biomass through the fermentation process yields biomethane and bioethanol, thermochemical conversion results in bio-oil production, and transesterification of lipids yields a biodiesel product. Some algal species have the ability to produce hydrogen through photobiological processes. The advantage of microalgal biomass over traditional energy-plant sources of biomass is the rapid growth rate of microalgae and accumulation of substantial amounts of carbohydrates and fats [3].

Microalgae are of interest for biotechnological purposes because of the ability to accumulate and store secondary metabolites and to efficiently produce functionally active proteins. The biotechnological potential of microalgae is related to the fact that their biomass contains valuable components, including lipids, starch, and alkanes [4]. Therefore, microalgal biomass is considered as one of the promising feedstock for biofuels and chemicals. Microalgae are used in the production of diverse components, e.g., dyes, antioxidants, gelling agents, emulsifiers, aminoacids, and 
fatty acids omega 3 and 6 [5]. Microalgal pigments and proteins have great potential for medical application [6]. Microalgal hydrocarbons and polysaccharides can be converted into ethylene, propylene, adipic acid, and furabics [4].

Environmental factors that exert an impact on microalgal growth include temperature, $\mathrm{pH}$, salinity, inorganic carbon availability, and light. Light is one of the key factors that control the course of physiological processes in microalgae. The quantity and quality of light determines the amount of available energy that is indispensable for the photosynthetic process. Equally important is the dark/light regime, which influences algal growth and biomass production. In the natural environment, light intensity undergoes continuous changes, and the light regimen is not constant [7]. Changes in light quantity induce alterations in the biochemical composition of microalgae. Increased frequencies of the light/dark cycles may considerably enhance productivity and photosynthetic efficiency [8]. Recently, investigations concerning the influence of the photoperiod on the biomass yield in several freshwater and marine microalgae, e.g., Chlamydomonas reinhardtii, Chlorella sorokiniana, Dunaliella tertiolecta [9], Chlorella vulgaris [7], have been carried out.

Individual algal species differ in terms of nutritional and light requirements, life cycles, and modes of reproduction. Therefore, culture conditions have a substantial effect on the algal proliferation rate and biomass production.

The aim of the study was to compare the growth rate and biomass productivity of five chlorophyte species of different reproduction modes: Scenedesmus obliquus, Botryococcus braunii, Neochloris conjuncta, Neochloris terrestris and Neochloris texensis. The three latter species from the Neochloris genus have not been studied yet.

\section{Materials and methods}

Strains of the green microalgae B. braunii SAG 30.81, S. obliquus SAG 276-3a, N. conjuncta SAG 78.80, $N$. terrestris UTEX B. 947, and N. texensis SAG 99.80 originating from the SAG Culture Collection of Algae and the UTEX Culture Collection of Algae were inoculated from solid into sterile liquid Kessler's medium to obtain a sufficiently large quantity of algal biomass required for the experiments. Preliminary semi-continuous cultures were run under light (Osram L58W/765 cool daylight) and temperature $24 \pm 1{ }^{\circ} \mathrm{C}$ for 60 days until biomass suitable for the experiments was obtained. The intensity of photosynthetically active light (PPFD) was $60 \mu \mathrm{mol} \mathrm{m} \mathrm{m}^{-2} \mathrm{~s}^{-1}$.

The biomass obtained was used (1) for determination of the relationship curves between the optical density of algal culture measured with the spectrophotometric method (Unicam Helios, UK) at the 650-nm wavelength and the dry weight (determined with the weighing method) of algae growing under the conditions specified above, and (2) as an inoculum for the growth experiments.

\section{Phototrophic cultivation}

The growth of the stationary cultures of the individual algal species on the sterile liquid Kessler's medium under the aforementioned conditions was monitored for 10 days at constant 24-h illumination (experimental variant I) or at a 12:12-h light:dark cycle (variant II). The initial dry weight content for cultures of each alga was $20 \mathrm{mg}$ dry weight/L and the initial optical densities $\left(\mathrm{OD}_{650}\right)$ for the cultures of particular species were as follows: B. braunii 0.031, S. obliquus $0.049, N$. conjuncta $0.025, N$. terrestris 0.032 , and N. texensis 0.037 . The medium used in this study contained: $\mathrm{KNO}_{3} 0.81 \mathrm{~g}, \mathrm{NaCl} 0.47 \mathrm{~g}, \mathrm{NaH}_{2} \mathrm{PO}_{4} \cdot 2 \mathrm{H}_{2} \mathrm{O}$ $0.47 \mathrm{~g}, \mathrm{Na}_{2} \mathrm{HPO}_{4} \cdot 12 \mathrm{H}_{2} \mathrm{O} 0.36 \mathrm{~g}, \mathrm{MgSO}_{4} \cdot 7 \mathrm{H}_{2} \mathrm{O} 0.25 \mathrm{~g}$, $\mathrm{CaCl}_{2} \cdot 2 \mathrm{H}_{2} \mathrm{O} 0.014 \mathrm{~g}, \mathrm{FeSO}_{4} \cdot \mathrm{H}_{2} \mathrm{O} 0.006 \mathrm{~g}, \mathrm{MnCl}_{2} \cdot 4 \mathrm{H}_{2} \mathrm{O}$ $0.0005 \mathrm{~g}, \quad \mathrm{H}_{3} \mathrm{BO}_{3} \quad 0.0005 \mathrm{~g}, \quad \mathrm{ZnSO}_{4} \cdot 7 \mathrm{H}_{2} \mathrm{O} \quad 0.0002 \mathrm{~g}$, $\mathrm{ZnSO}_{4} \cdot 7 \mathrm{H}_{2} \mathrm{O} 0.0002 \mathrm{~g},\left(\mathrm{NH}_{4}\right)_{6} \mathrm{Mo}_{7} \mathrm{O}_{24} \cdot 4 \mathrm{H}_{2} \mathrm{O} 0.00002 \mathrm{~g}$, EDTA (Titriplex III Merck) $0.008 \mathrm{~g} / \mathrm{L}, \mathrm{pH}$ 7.0. The cultures were mixed by means of sterile air.

The growth of each culture was monitored daily for 10 days by spectrophotometric measurements of the optical density $\mathrm{OD}_{650}$, typical for live cells. Dry weight (DW) of algal biomass was determined after overnight drying at $90{ }^{\circ} \mathrm{C}$.

A good linear relationship was found between the algal dry weight and the optical density $\left(\mathrm{OD}_{650}\right)$ of the cultures. The correlation coefficients $R^{2}$ were close to the value of $1.0(0.9991-0.9999)$ in the case of the algal strains from the genus Neochloris; they were only slightly lower (0.9965-0.9982) for the other strains. This allowed monitoring the changes in the algal growth and biomass in the liquid cultures with the use of the spectrophotometric method. All the experiments and determination were performed in triplicate.

Based on the curves of the correlations between $\mathrm{OD}_{650}$ and dry weight, the algal growth curves, biomass doubling time, changes in the specific growth rate in different culture phases (0-3 days, 3-10 days), and biomass productivity (after 10 days of cultivation) were determined. The specific growth rate of the microalgae was calculated using the equation $\mu=\ln \left(\mathrm{N}_{2} / \mathrm{N}_{1}\right) /\left(t_{2}-t_{1}\right)$, where $\mu$ is the specific growth rate, and $\mathrm{N}_{1}$ and $\mathrm{N}_{2}$ are the biomass at time $1\left(t_{1}\right)$ and time $2\left(t_{2}\right)$, respectively.

\section{Results}

The culture growth of the examined algal species differed and was dependent on the photoperiod applied (Figs. 1,2). 
Fig. 1 Comparison of growth of five green microalgae under continuous illumination. Data are expressed as mean $\pm \mathrm{SD}$, $n=3$
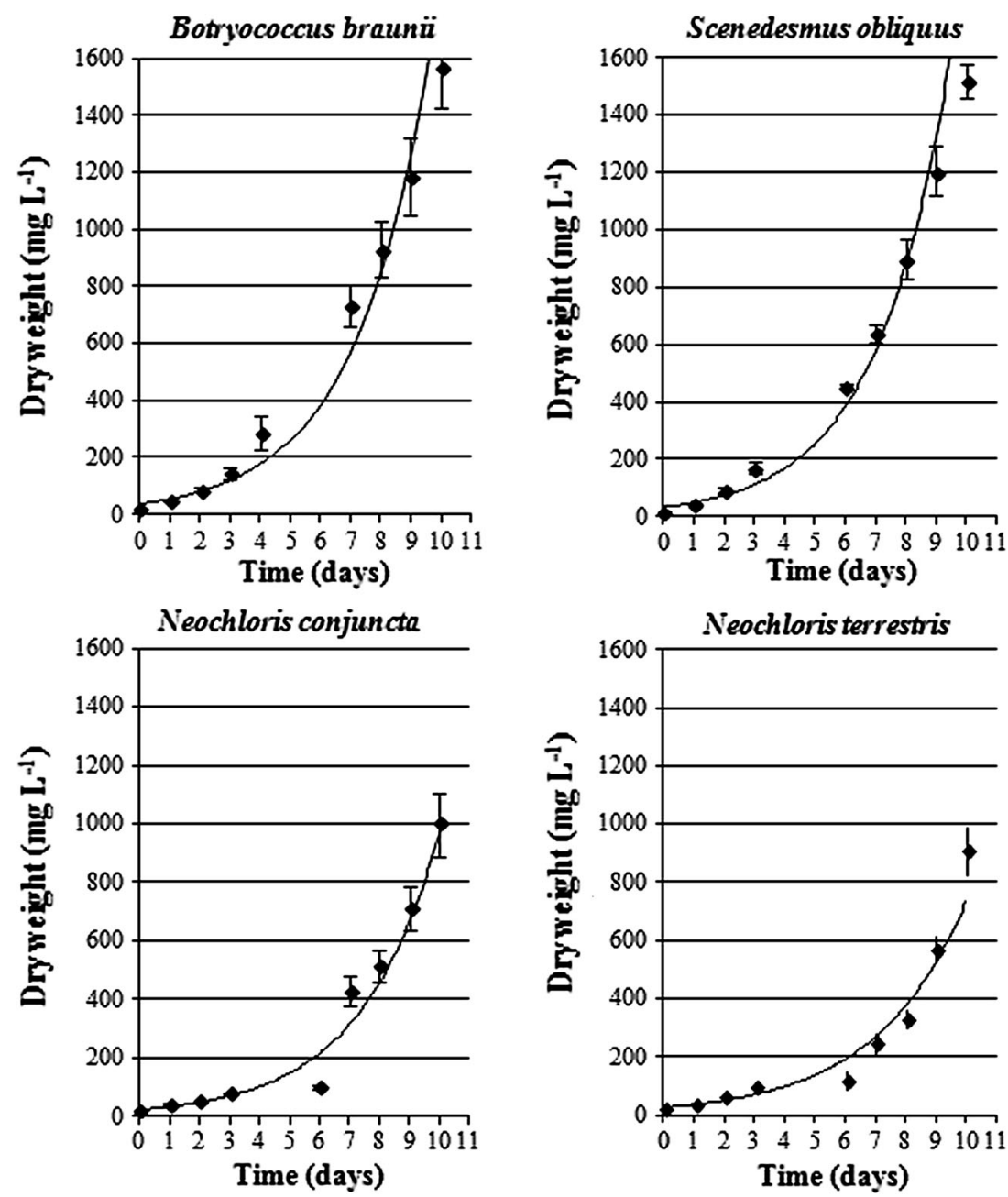

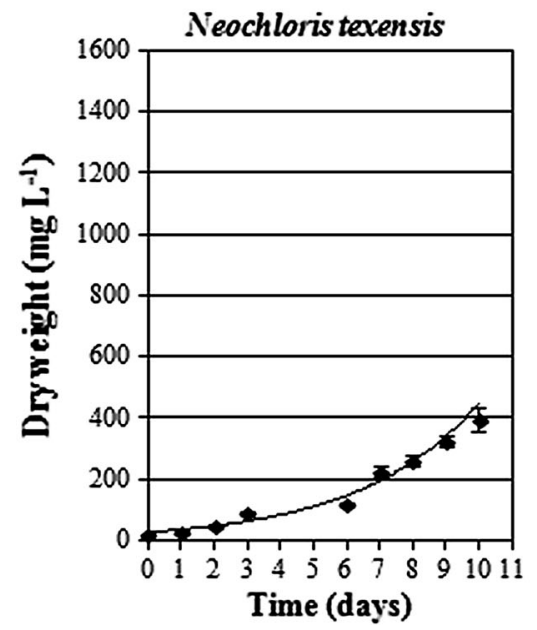

Continuous illumination stimulated the growth of $B$. braunii and S. obliquus more efficiently than the growth of the microalgal strains from the genus Neochloris (Fig. 1). In contrast, shorter duration of light (12L:12D photoperiod) led to increased growth of the three Neochloris species (Fig. 2). The effect of the light regime on the specific growth rate assessed in two phases: days 0-3 and days 3-10 of the culture is shown in Fig. 3. Under continuous illumination (Fig. 3a), the specific growth rate of $B$. braunii and $S$. obliquus in the first growth phase (up to 3 days) was generally higher ( $\mu=0.66$ and 0.71 day $^{-1}$, respectively) than that of the other strains ( $N$. terrestris: $\mu=0.52$ day $^{-1}, N$. texensis: $\mu=0.49$ day $^{-1}, N$. conjuncta: $\mu=0.44$ day $\left.^{-1}\right)$. The use of the more energy-efficient (in economic terms) 12L:12D 
Fig. 2 Growth curves of green microalgae under the 12L:12D cycle. Data are expressed as mean $\pm \mathrm{SD}, n=3$
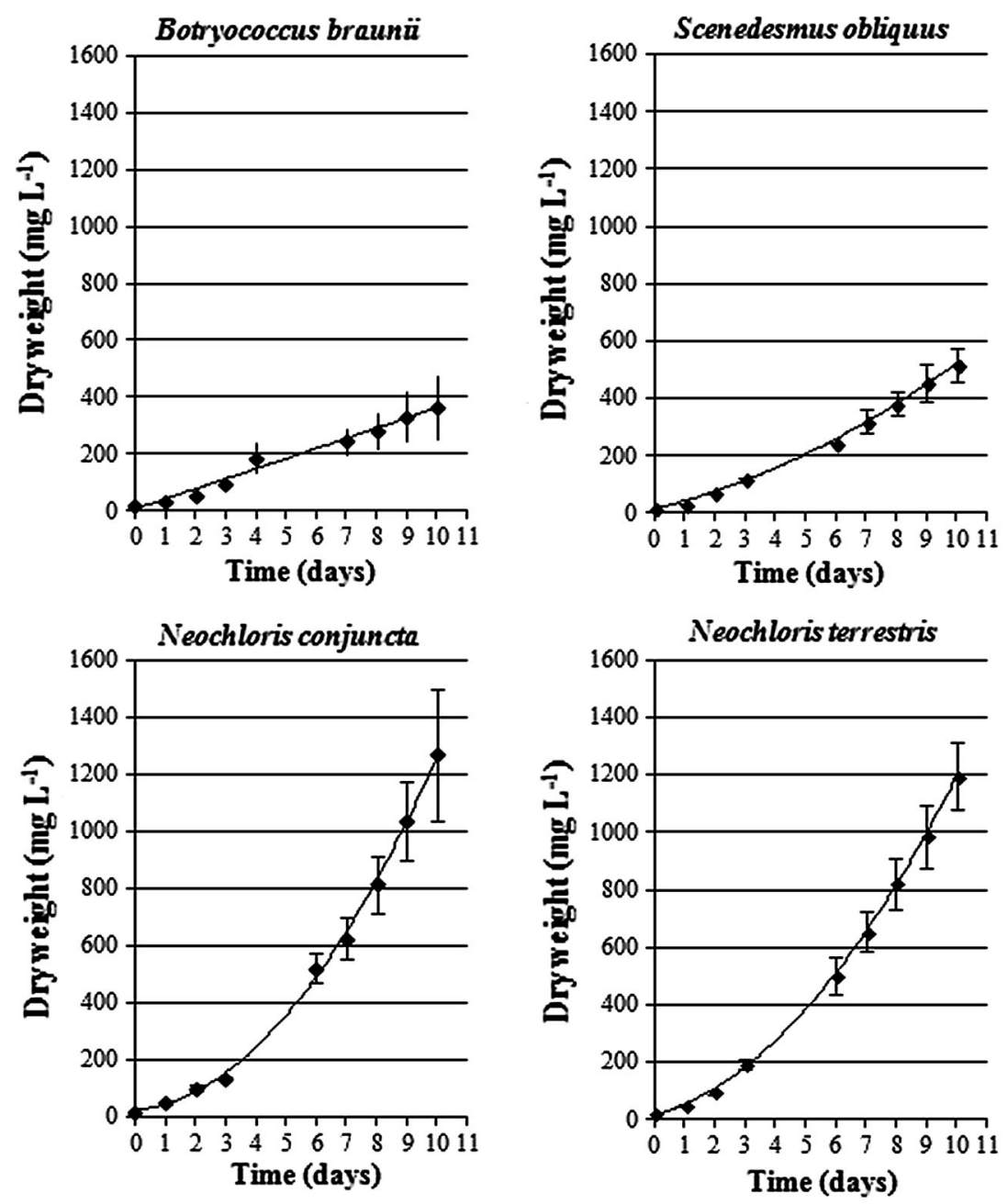

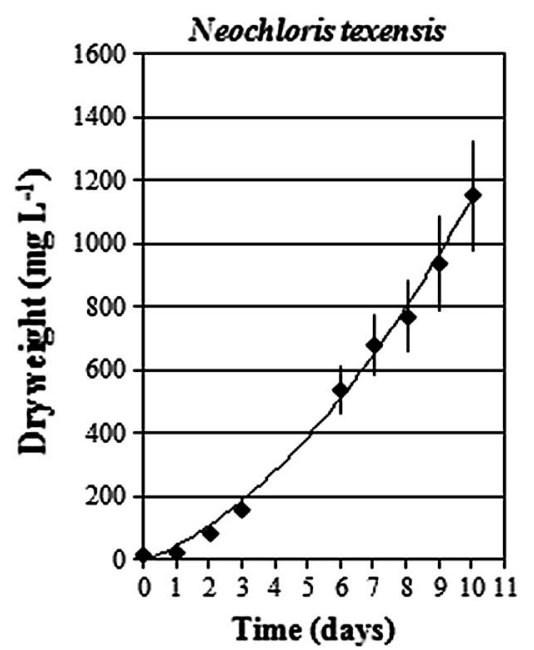

cycle (Fig. 3 b) resulted in a decrease in the growth rate of $B$. braunii and $S$. obliquus, which was then lower than the growth rate of the three Neochloris species examined. At the 12L:12D photoperiod, the growth rate in the first phase of the culture (0-3 days) in all the Neochloris strains analyzed (N. terrestris: $\mu=0.75$ day $^{-1}, N$. texensis: $\mu=0.71$ day $^{-1}$,
$N$. conjuncta: $\mu=0.66$ day $^{-1}$ ) was generally higher than that in B. braunii and S. obliquus. In the second culture phase (3-10 days), the 12L:12D light regime also supported the higher growth rate of Neochloris than that of the other two algal species. The effect of the photoperiod on the biomass doubling time is summarized in Table 1. A 
Fig. 3 Specific growth rate in the green microalgae within 2 phases $(0-3$ days and 3-10 days) of culture under various photoperiods. a Continuous light; b 12L:12D cycle
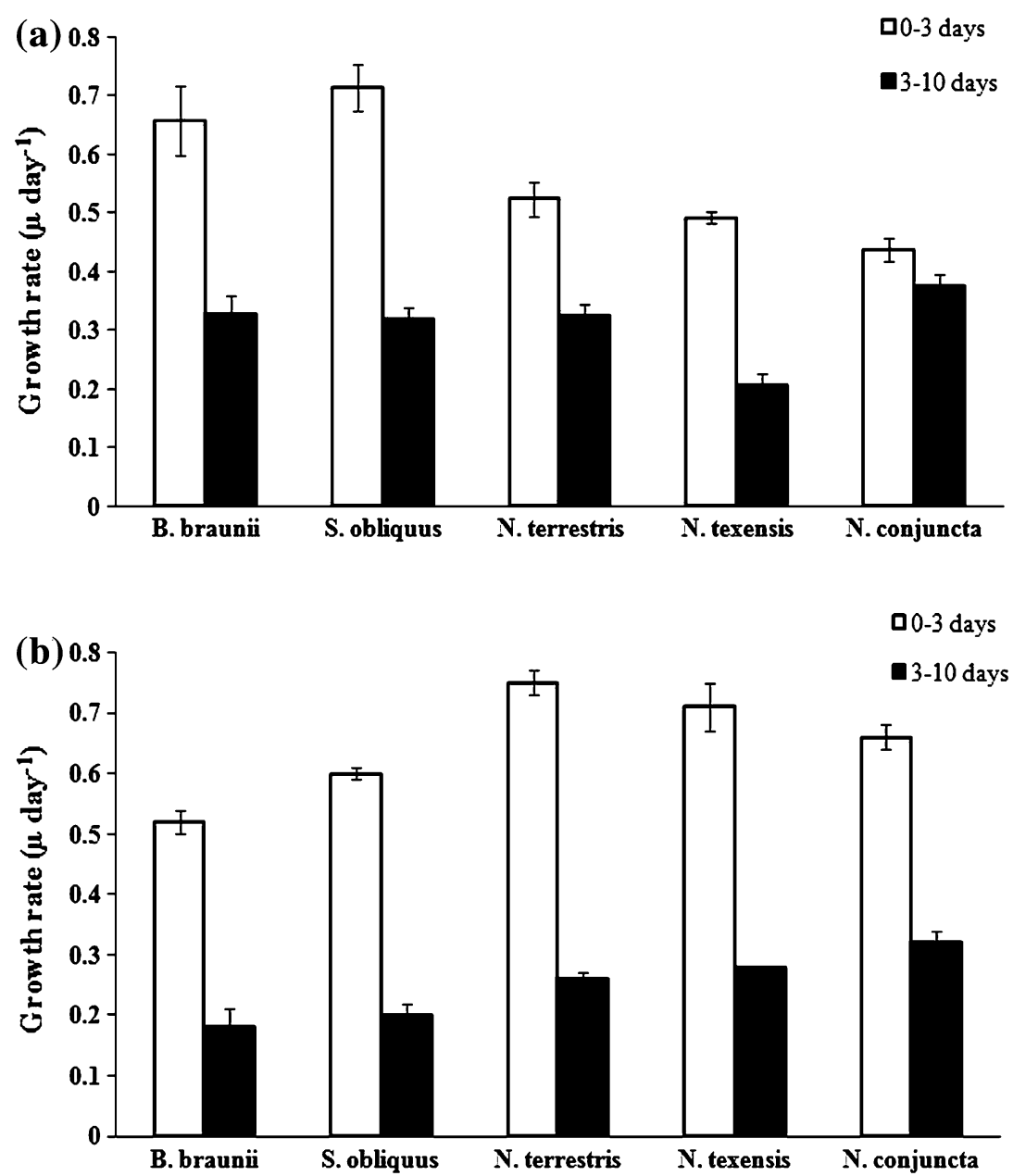

Table 1 Biomass doubling time (h) in algal cultures growing at different photoperiods

\begin{tabular}{lll}
\hline Algal species & \multicolumn{2}{l}{ Photoperiod } \\
\cline { 2 - 3 } & 24 h light & 12 h light:12 h dark \\
\hline B. braunii & $18.7( \pm 0.55)$ & $36.5( \pm 1.43)$ \\
S. obliquus & $22.2( \pm 0.26)$ & $28.0( \pm 0.57)$ \\
N. conjuncta & $24.9( \pm 2.12)$ & $17.6( \pm 1.14)$ \\
N. terrestris & $27.8( \pm 2.17)$ & $19.7( \pm 0.59)$ \\
N. texensis & $30.9( \pm 1.97)$ & $32.4( \pm 0.78)$ \\
\hline
\end{tabular}

Data are expressed as mean $\pm \mathrm{SD}, n=3$

comparison of all the species tested under continuous illumination revealed the shortest biomass doubling time for B. braunii ( $18.7 \mathrm{~h}$, at continuous illumination) and for $N$. conjuncta $(17.6 \mathrm{~h})$ as well as $N$. terrestris $(19.7 \mathrm{~h})$ under the 12L:12D cycle. B. braunii and S. obliquus were characterized by a much shorter biomass doubling time in the constantly illuminated cultures than under the 12L:12D cycle. In turn, $N$. conjuncta and $N$. terrestris exhibited a considerably shorter biomass doubling time under the 12L:12D cycle than under continuous light. The different
Table 2 Biomass productivity $\left(\mathrm{g} \mathrm{L}^{-1}\right.$ day $\left.^{-1}\right)$

\begin{tabular}{lll}
\hline Algal species & \multicolumn{2}{l}{ Photoperiod } \\
\cline { 2 - 3 } & 24 h light & 12 h light:12 h dark \\
\hline B. braunii & $0.155( \pm 0.014)$ & $0.034( \pm 0.011)$ \\
S. obliquus & $0.150( \pm 0.006)$ & $0.050( \pm 0.006)$ \\
N. conjuncta & $0.098( \pm 0.011)$ & $0.125( \pm 0.023)$ \\
N. terrestris & $0.089( \pm 0.008)$ & $0.117( \pm 0.012)$ \\
N. texensis & $0.037( \pm 0.004)$ & $0.114( \pm 0.017)$ \\
\hline
\end{tabular}

Data are expressed as mean $\pm \mathrm{SD}, n=3$

photoperiods did not influence essentially the doubling time of $N$. texensis.

The light regime had an essential effect on the microalgal biomass productivity. The productivity of the individual strains was correlated with the photoperiod applied (Table 2). The maximum biomass productivity was obtained in B. braunii and S. obliquus $(0.155$ and $0.150 \mathrm{~g} \mathrm{~L}^{-1} \mathrm{day}^{-1}$, respectively) cultured under the continuous light conditions. All the Neochloris species grew more efficiently at the $12 \mathrm{~L}: 12 \mathrm{D}$ cycle than under continuous illumination and the biomass productivity of all the 
three Neochloris species was even two-threefold higher $\left(0.114-0.125 \mathrm{~g} \mathrm{~L}^{-1} \mathrm{day}^{-1}\right)$ than that of B. braunii and S. obliquus (0.034 and $0.050 \mathrm{~g} \mathrm{~L}^{-1} \mathrm{day}^{-1}$, respectively).

\section{Discussion}

Light intensity and photoperiod is one of the most important factors influencing the growth rate and biomass composition and, hence, production of high-value microalgal products in a wide range of algal species [7, 10-14]. Alterations in the photoperiod induce changes in the total protein, pigment and fatty acid content in $C$. vulgaris [13]; the growth and lipid production in Porphyridium cruentum [12] and B. braunii [15]; cell density, the cell growth rate and total lipid content in Nannochloropsis sp. [14]; biomass production and utilization of nutrients (nitrate and phosphate) by Tetraselmis chui [11] and biomass production in cyanobacterium Aphanothece [21].

The photoperiod is also important in terms of the economic aspect if algal biomass is produced with a supply of light from artificial sources. There are several reports on the influence of the photoperiod on the productivity and growth rate of C. vulgaris [7] and Dunaliella spp. [9], on the biomass concentration of B. braunii [15] and biomass growth of $S$. obliquus [16]. However, there are many other algal species that are potentially used for biomass production. No study on the unicellular green microalgae Neochloris spp. (except from $N$. oleoabundans) has been reported up to date. As shown by our results, the Neochloris coccoid microalgae display biomass productivity comparable to the widely described B. braunii and S. obliquus but at a lower "light energy input", thus making them promising biotechnological objects. Recently, Khoeyi et al. [7] have reported that the light regime is an important factor controlling the biomass production of $C$. vulgaris. Longer duration of light resulted in increased biomass of $C$. vulgaris at different light intensities, and the increased specific growth rate was associated with an increase in light duration. These results are similar to these obtained in the present study for $B$. braunii and S. obliquus, for which the increased duration of light improved the specific growth rate. As shown in Fig. 3, the maximum specific growth rate was found for B. braunii and S. obliquus $\left(0.64\right.$ and $0.71 \mu$ day $^{-1}$, respectively) under the 24-h light regime. The present study has shown a 4.5 -fold higher $(0.155$ vs. $0.034 \mathrm{~g} \mathrm{~L}^{-1} \mathrm{day}^{-1}$ ) biomass productivity of $B$. braunii under the continuous illumination in comparison with the 12L:12D cycle. This result is comparable to that obtained by Ruangsomboon [15], who reported that the total biomass concentration in B. braunii was $1.91 \pm 0.24 \mathrm{~g} \mathrm{~L}^{-1}$ under a 24:0-light cycle, which was four times higher than the biomass obtained under the 12L:12D cycle. The biomass productivity of $B$. braunii and $S$. obliquus obtained under continuous illumination $\left(0.155\right.$ and $0.150 \mathrm{~g} \mathrm{~L}^{-1}$ day $^{-1}$ respectively) was slightly lower than the productivity of some Chlorella spp. The biomass productivity of different Chlorella strains ranged $0.18-0.34 \mathrm{~g} \mathrm{~L}^{-1} \mathrm{day}^{-1}$ $[17,18]$. Kim et al. [19] reported that the specific growth rate and biomass productivity of Chlorella sp. under a $\mathrm{CO}_{2}$ concentration $0.04 \%$ and $100 \mu \mathrm{mol} \mathrm{m}^{-2} \mathrm{~s}^{-2}$ were $0.50 \mu$ day $^{-1}$ and $0.24 \mathrm{~g} \mathrm{~L}^{-1}$ day $^{-1}$, respectively. The productivity of $C$. vulgaris [7] under limited time of illumination (12L:12D) and very similar light intensity $\left(62.5 \mu \mathrm{mol} \mathrm{m}^{-2} \mathrm{~s}^{-1}\right)$ was as such in B. braunii and S. obliquus (at $24 \mathrm{~h}$ illumination) in our study. Higher light intensity decreased Chlorella productivity. Ho et al. [20] reported that the biomass productivity of six tested S. obliquus strains ranged from $0.217 \pm 0.02 \mathrm{~g} \mathrm{~L}^{-1} \mathrm{day}^{-1}$ to $0.441 \pm 0.016 \mathrm{~g} \mathrm{~L}^{-1} \mathrm{day}^{-1}$ under continuous illumination but at higher intensity $\left(140 \mu \mathrm{mol} \mathrm{m} \mathrm{m}^{-2} \mathrm{~s}^{-1}\right)$. In those experiments, $\mathrm{CO}_{2}(2.5 \%)$ was introduced into the algal cultures continuously, which may have contributed to the higher productivity of S. obliquus. In our study, the biomass productivity of $S$. obliquus under continuous illumination $\left(60 \mu \mathrm{mol} \mathrm{m}{ }^{-2} \mathrm{~s}^{-1}\right)$ without $\mathrm{CO}_{2}$ enrichment was low $\left(0.150 \pm 0.006 \mathrm{~g} \mathrm{~L}^{-1} \mathrm{day}^{-1}\right)$.

Jacob-Lopes et al. [21] evaluated the growth of the bluegreen microalga Aphanothece under different illumination cycles $(0: 24,2: 22,4: 20,6: 18,8: 16,10: 14,12: 12,14: 10$, 16:8, 18:6, 20:4, 22:2, and 24:0 (night:day). They found a linear reduction in biomass production with reduction in the duration of the light period, with the exception of the 12:12 (night:day) cycle. Under the conditions of the 12:12 (night:day) photoperiod, the species exhibited higher productivity and maximum cell density than under the other photoperiods applied. Toro [22] reported equal growth rates of the microalgae Chaetoceros gracilis (a diatom) and Isochrysis galbana (a haptophyte) under the 0:24 and 12:12 (night:day) regimes; however, the cultures growing at the 12:12 photoperiod were supplied with double light intensity. This implies that the cell growth was also affected by the amount of energy offered per cycle, and not only by the duration of the photoperiod. However, as found for the green microalga $C$. vulgaris [7], the increase in light intensity from 60 to $100 \mu \mathrm{mol} \mathrm{m}{ }^{-2} \mathrm{~s}^{-1}$ did not exert any positive effect on its biomass productivity.

The varied productivity and growth rate of the algal species investigated in the present work were dependent on the photoperiod and were species specific (over the same taxonomic group Chlorophyceae). The algae studied can be classified into two groups: one growing more efficiently at continuous light (B. braunii and S. obliquus) and the second one (3 species of Neochloris) growing more efficiently under the 12L:12D regime. These two groups of 
microalgae differ in the reproduction mode. $B$. braunii and $S$. obliquus reproduce exclusively by autospores [23], while the species from the genus Neochloris reproduce by aplanospores or motile zoospores released from cells in darkness [24, 25]. So far, only $N$. oleoabundans has been the object of detailed investigations due to its valuable features [26]. The other unicellular species of the green coccoid algae from the genus Neochloris (N. terrestris, $N$. texensis, $N$. conjuncta), examined for the first time in this study and exhibiting two modes of reproduction dependent on light conditions, seem to be promising prospective objects for algal biotechnology.

Acknowledgments This work was funded in part by the National Science Centre, Poland (Grant No. N310 036 32/1951) in 2011-2014.

Open Access This article is distributed under the terms of the Creative Commons Attribution License which permits any use, distribution, and reproduction in any medium, provided the original author(s) and the source are credited.

\section{References}

1. Chen C, Yeh K, Aisyah R, Lee D, Chang J (2011) Cultivation, photobioreactor design and harvesting of microalgae for biodiesel production: a critical review. Bioresour Technol 102:71-81

2. Li Y, Horsman M, Wu N, Lan CQ, Dubois-Calero N (2008) Biofuels from microalgae. Biotechnol Prog 24:815-820

3. Brennan L, Owende P (2010) Biofuels from microalgae: a review of technologies for production, processing, and extractions of biofuels and co-products. Renew Sustain Energ Rev 14:557-577

4. Wijffels RH, Kruse O, Hellingwerf KJ (2013) Potential of industrial biotechnology with cyanobacteria and eukaryotic microalgae. Curr Opin Biotechnol 24:405-413

5. Alonso M, Lago FC, Vieites JM, Espineira M (2012) Molecular characterization of microalgae used in aquaculture with biotechnology potential. Aquac Int 20:847-857

6. Yen HW, Hu IC, Chen CY, Ho SH, Lee DJ, Chang JS, Chang JS (2013) Microalgae-based biorefinery: from biofuels to natural products. Bioresour Technol 135:166-174

7. Khoeyi ZA, Seyfabadi J, Ramezanpour Z (2012) Effect of light intensity and photoperiod on biomass and fatty acid composition of the microalgae, Chlorella vulgaris. Aquac Int 20:41-49

8. Grobbelaar JU (2009) Upper limits of photosynthetic productivity and problems of scaling. J Appl Phycol 21:519-522

9. Janssen M (2002) Cultivation of microalgae: effect of light/dark cycles on biomass yield. Thesis Wageningen University, Wageningen, Ponsen\&Looijen BV, The Netherland

10. Fabregas J, Maseda A, Dominguez A, Ferreira M, Otero A (2002) Changes in the cell composition of the marine microalga,
Nannochloropsis gaditana, during a light:dark cycle. Biotechnol Lett 24:1699-1703

11. Meseck SL, Alix JH, Gary H, Wikfors GH (2005) Photoperiod and light intensity effects on growth and utilization of nutrients by the aquaculture feed microalga, Tetraselmis chui (PLY429). Aquaculture 246:393-404

12. Oh SH, Han JG, Kim Y, Ha JH, Kim SS, Jeong MH, Jeong HS, Kim NY, Cho JS, Yoon WB, Lee SY, Kang DH, Lee HY (2009) Lipid production in Porphyridium cruentum grown under different culture conditions. J Biosci Bioeng 108(5):429-434

13. Seyfabadi J, Ramezanpour Z, Khoeyi ZA (2011) Protein, fatty acid, and pigment content of Chlorella vulgaris under different light regimes. J Appl Phycol 23:721-726

14. Wahidin S, Idris A, Shaleh SR (2013) The influence of light intensity and photoperiod on the growth and lipid content of microalgae Nannochloropsis sp. Bioresour Technol 129:7-11

15. Ruangsomboon S (2012) Effect of light, nutrient, cultivation time and salinity on lipid production of newly isolated strain of the green microalga, Botryococcus braunii KMITL 2. Bioresour Technol 109:261-265

16. Mata TM, Melo AC, Simoes M, Caetano NS (2012) Parametric study of a brewery effluent treatment by microalgae Scenedesmus obliquus. Bioresour Technol 107:151-158

17. de Greque MM, Costa JAV (2007) Carbon dioxide fixation by Chlorella kessleri, C. vulgaris, Scenedesmus obliquus and Spirulina sp. cultivated in flasks and vertical tubular photobioreactors. Biotechnol Lett 29:1349-1352

18. Ryu HJ, Oh KK, Kim YS (2009) Optimization of the influential factors for the improvement of $\mathrm{CO}_{2}$ utilization efficiency and $\mathrm{CO}_{2}$ mass transfer rate. J Ind Eng Chem 15:471-475

19. Kim W, Park JM, Gim GH, Jeong S, Kang CM, Kim D, Kim SW (2012) Optimization of culture conditions and comparison of biomass productivity of three green algae. Bioprocess Biosyst Eng 35:19-27

20. Ho S, Chen C, Chang J (2012) Effect of light intensity and nitrogen starvation on $\mathrm{CO}_{2}$ fixation and lipid/carbohydrate production of an indigenous microalga Scenedesmus obliquus CNWN. Bioresour Technol 113:244-252

21. Jacob-Lopes E, Scoparo C, Lacerda L, Franco T (2009) Effect of light cycles (night/day) on $\mathrm{CO}_{2}$ fixation and biomass production by microalgae in photobioreactors. Chem Eng Process 48: 306-310

22. Toro JE (1989) The growth rate of two species of microalgae used in shellfish hatcheries cultured under two light regimes. Aqua Fish Manag 20:249-254

23. John DM, Whitton BA, Brook AJ (2002) The freshwater algal flora of the British Isles: an identification guide to freshwater and terrestrial algae. Cambridge University Press, Cambridge

24. Ettl H, Gärtner G (1995) Syllabus der Boden- Luft- und Flechtenalgen. Fischer G Verlang Stuttgart Jena, New York

25. Van den Hoek C, Mann DG, Jahns HM (1995) Algae. An introduction to phycology. Cambridge University Press, Cambridge, p 623

26. Murray KE, Healy FG, McCord RS, Shields JA (2011) Biomass production and nutrient uptake by Neochloris oleoabundans in an open through system. Appl Microbiol Biotechnol 90:89-95 